\title{
Problems with disseminating information on disease control in wheat and barley to farmers
}

\author{
Lise Nistrup Jørgensen • Egon Noe • \\ Ghita C. Nielsen • Jens Erik Jensen • \\ Jens Erik Ørum • Hans O. Pinnschmidt
}

Received: 25 May 2007 / Accepted: 22 November 2007

(C) KNPV 2007

\begin{abstract}
Plant pathologists have traditionally worked in the area of clarifying and understanding the disease cycles of specific diseases, factors influencing epidemiology, yield loss potential and host-pathogen interactions in order to be able to minimise the disease risk, build warning systems or recommend specific control thresholds in relation to the application of fungicides. The decision support system Crop Protection Online (CPO) is an example of a threshold-based system that determines economically viable fungicide strategies. The system is based on using appropriate doses aimed
\end{abstract}

L. N. Jørgensen $(\bowtie) \cdot$ H. O. Pinnschmidt

Faculty of Agricultural Sciences, Department of Integrated Pest Management, University of Aarhus,

4200 Slagelse, Denmark

e-mail: Lisen.jorgensen@agrsci.dk

\section{E. Noe}

Faculty of Agricultural Sciences,

Department of Agroecology and Environment,

University of Aarhus,

8830 Tjele, Denmark

G. C. Nielsen · J. E. Jensen

The Danish Advisory Services,

Udkærsvej 15,

8200 Skejby, Denmark

\section{J. E. Ørum}

Faculty of Life Sciences, Food and Resource Economics Institute, University of Copenhagen,

Rolighedsvej,

Copenhagen, Denmark at minimising the overall pesticide input. CPO is used widely by advisors and many of the thresholds are generally accepted and disseminated through newsletters. The national figures for the use of fungicides in cereals have shown a major reduction during the last 20 years and their use today is much in line with the level that can be achieved from using CPO as indicated from validation trials. The number of end-users among farmers has been stable at around 3\% during the last 10 years (800-1,000 farmers). Major hurdles in increasing the number of users are believed to be: (1) the requirements for carrying out assessments in the field, (2) farm sizes getting larger, leaving less time for decision making for individual fields, (3) lack of economic incentives to change from standard treatments, (4) the failure of decision support systems to interact with other computer-based programmes on the farm, (5) the lack of compatibility of decision support systems with farmers' ways of making decisions on crop protection in general, (6) the need for direct interactions with advisors. A sociological investigation into the farmers' way of making decisions in the area of crop protection has shown that arable farmers can be divided into three major groups: (a) systems-orientated farmers, (b) experienced-based farmers and (c) advisory-orientated farmers. The information required by these three groups is different and has to be looked at individually from the end-user's perspective rather than from the scientist's perspective. New ways of entering the decision support system where specific 
field inspections are omitted and where regional disease data are relied on, have been investigated and tested in field trials. The results show possibilities for further developments in that direction, which might be one way of gaining more end-users.

Keywords Decision support system · Disease thresholds · Eco-sociological barriers · Farmer types . Winter wheat

\section{Introduction}

Legislation and limitations have been imposed on the use of pesticides in many countries in northern Europe for the last 20-25 years. Based on these national action plans, it has become important to encourage a low pesticide input strategy. Similar proposals to eliminate unnecessary use are also stated in the EU's Thematic Strategy on the Sustainable Use of Pesticides (Anonymous 2006b). In order to eliminate unnecessary use of fungicides, precise knowledge of the disease risk of an epidemic at field level is essential. In order to achieve this, it is very important to provide farmers with simple and robust methodologies to assess disease occurrence or risk in order to judge whether fungicides should be applied (Hansen et al. 1994; Jørgensen et al. 1996; Verret et al. 2000).

The development of thresholds, models and decision support systems (DSS) to farmers and advisors covering this need started in the late 1980s. EPIPRE was one of the first systems to be developed (Zadoks 1983). Several other systems have been developed since and new systems are still entering the field today (Röhrig 2006). Among the systems that have been on the market for the longest time are Pro_Plant and Crop Protection Online (CPO); both systems are today Internet-based (Rydahl et al. 2003; Volk et al. 2003).

More specifically, the Danish DSS CPO is a threshold-based system that determines economically viable strategies for control of diseases, pests and weeds using low pesticide input (Secher et al. 1995; Rydahl 2003). The system is designed to support advisors and farmers when they make decisions about crop protection in arable crops. CPO consists of three parts: (1) encyclopaedic information on pests, diseases and weeds, (2) recommendations for control of pests and diseases of cereals and (3) recommendations for control of weeds in the major crops grown in Denmark. The models focus on optimising the input and minimising the cost of controlling a given problem seen in the field. Calculation of the optimal pesticide dose is therefore an important output. Focus on control strategies on diseases has been not only to look for the best disease control but also to optimise net yield rather than gross yield (Jørgensen et al. 2000). CPO is part of Planteinfo (http://www.Planteinfo.dk), which, among other things, features access to climate data, a pesticide database and a cultivar database covering the major crops grown in Denmark.

Based on field trial studies, CPO has shown a significant potential for reducing the use of herbicides in particular compared to the common spraying practice. Due to the proven reduction potential, there has been a significant interest among politicians to ensure a more widespread use of the system. This is in line with the pesticide reduction schemes implemented in Denmark for more than 20 years (Jørgensen and Kudsk 2006).

CPO is used by nearly all Danish advisors (approximately 420) in the field of arable production, and approximately $3 \%$ of Danish farmers subscribe to the system. These user numbers have been fairly stable for approximately 10 years. It has often been discussed whether it would be possible to increase the number of farmers using the system. However, and unfortunately, this has proven to be very difficult. The main obstacle is the time-consuming field registrations, which are necessary for the models to calculate field-specific recommendations. Historically, it has proven difficult to stimulate farmers to use DSS (McCown 2002). It has been shown previously that farmers have different expectations of decision-making tools depending on their styles of farming (Noe and Halberg 2002).

The major objective of this paper is to summarise the state of the art in Denmark with respect to practical disease control in winter wheat. The paper gives examples of thresholds used in $\mathrm{CPO}$ and results from applying and validating the existing system. A sociological investigation with focus on the potential use and barriers to applying an existing decision support system like CPO is reported. Results from trials investigating possibilities of avoiding time-demanding field registrations are also presented. The results are discussed from both an agronomic and a socio-economic angle. The results are based on a project covering both weed and disease control in cereals in order to validate the 
potential from the DSS and other means of disseminating information. This paper focuses on elements concerned with disease control in cereals.

\section{Methods}

Agronomic evaluation of the system

Since the early development of CPO, control thresholds have been developed empirically and validated in field trials in order to investigate whether the recommendations given by the system are competitive with other fungicide recommendations. A total of 45 validation trials were carried out in winter wheat and 38 in spring barley distributed at different sites in Denmark which represent all relevant soil and climate conditions. The trials were conducted as standard field trials with four replicates and a randomised block design. The treatments applied in the CPO plots were based on weekly disease assessments in order to determine whether and when the disease thresholds were exceeded. Following the recommendations of different control strategies, disease assessments were carried out as per cent leaf area covered by each disease. Assessments were made at several growth stages, but the focus in this paper is on assessments carried out at approximately growth stage (GS) 75 . The plots were harvested with a plot combine harvester. The dry matter content was measured, and the grain yield was corrected to $15 \%$ moisture content. The benefit from fungicide treatment is represented in terms of yield, with deduction made to cover the cost of fungicide and its application costs. A grain price of $750 \mathrm{DKK} \mathrm{t}^{-1}$ was used for the calculations.

Investigation of new approaches to $\mathrm{CPO}$

During two seasons, a total of ten trials were carried out by the Danish Agricultural Advisory Service (DAAS) to compare the existing version of CPO with a new prototype, which, instead of using individual field information, relies on information from the national monitoring system using data from the nearest regional locality as a basis for assessing the need for control. The trials were carried out at ten sites in Denmark representing different soil types, climates and disease pressures. Disease assessments were all made as per cent leaf area covered by each disease. The plots were harvested with a plot combine harvester. The dry matter content was measured, and the grain yield was corrected to $15 \%$ moisture content.

Both in validation trials and trials investigating the new approach to CPO, spraying was carried out with a plot sprayer at low pressure ( $2-3$ bars) using flat fan nozzles and a water volume of 200-300 $1 \mathrm{ha}^{-1}$. Statistical analyses on the data were carried out using ANOVA, from which LSDs were calculated at the 95\% confidence level.

Sociological investigation on farmers' decision process on crop protection

The sociological investigation was based on a questionnaire with 746 returns and four focus group interviews in order to understand how farmers make their decisions with respect to using pesticides, and to explore the barriers to a more extensive use of the present CPO.

The method used to identify and analyse for ideal types was previously described by Weber (1922). The statistical technique used for analysing the questionnaire data was the categorical principal component analysis. Selected variables were used to construct a system of co-ordinates based on their inter-relationships. In this study, the procedure indicated three different types of decision-making strategies for arable farmers. Following this grouping, focus group interviews were carried out with farmers who had responded to the questionnaire in order to obtain a better understanding of the three types with respect to decision-making, actions and motivational logic. The exact classification of each decision-making strategy was made based on the characteristic ways in which the participants from each group made decisions. The method and the analyses of the data are described in further detail by Langvad and Noe (2006) and Jørgensen et al. (2007a).

\section{Results and discussion}

Thresholds and cultivar ranking in wheat

Examples of the thresholds used in CPO for control of wind and splash-borne diseases in wheat are shown in Table 1. The thresholds are based on many years of 
Table 1 List of some of the thresholds used for control of diseases in winter wheat in the decision support system Crop Protection Online (CPO)

Winter wheat

Eyespot

$>35 \%$ plants attacked at growth stage (GS) 30-32. Only main

shoots are assessed. The attack must spread to the next-to-theoutermost leaf sheath to be included

Powdery mildew

Susceptible cultivars: GS 29-31: $>10 \%$ plants attacked, GS 32-40: $>25 \%$ plants attacked

Non-susceptible and partly susceptible cultivars: GS 29-31: $>25 \%$ plants attacked, GS 32-40: $>50 \%$ plants attacked

Yellow rust

Susceptible cultivars: GS 29-60: >1\% plants attacked, GS 61-71: $>10 \%$ plants attacked

Non-susceptible cultivars: GS 29-60: $>10 \%$ plants attacked, GS $61-71:>75 \%$ plants attacked

Septoria

Susceptible cultivars: At least 4 days with precipitation $(>1 \mathrm{~mm})$ from GS 32. If the crop was sprayed before GS 52, the counting of days with precipitation begins after 10 days. If the crop is sprayed from GS 52 onwards, the counting of days with precipitation begins after 20 days. A maximum of 30 days are counted back in time. A spray is also triggered at GS 45-59 if $>10 \%$ of the plants show attack on the third leaf from the top. Control of septoria, if any, can be considered until GS 71

Tan spot

Only with wheat as previous crop and with reduced tillage between crops

Susceptible cultivars: GS 31-32: $>75 \%$ plants attacked, GS 33-60: $>25 \%$ plants attacked, GS 61-71: $>50 \%$ plants attacked
Brown rust

Susceptible cultivars: GS 30-31: $>25 \%$ plants attacked, GS 32-50: $>10 \%$ plants attacked, GS 51-71: $>25 \%$ plants attacked

Partly susceptible cultivars: GS 29-60: $>1 \%$ plants attacked, GS 61-71: $>50 \%$ plants attacked

Partly susceptible cultivars: At least 5 days with precipitation (more than $1 \mathrm{~mm}$ ) from GS 37. Control at GS 39 at the earliest. Otherwise as in susceptible cultivars

Only with wheat as previous crop and with reduced tillage between crops

Less susceptible cultivars: GS 37-60: $>50 \%$ plants attacked, GS 61-71: $>75 \%$ plants attacked empirical work (Jørgensen et al. 1996) and are occasionally revised if new information becomes available. Examples of recent changes include incorporation of thresholds for new diseases such as tan spot (Drechslera tritici-repentis; Jørgensen and Olsen 2007), adjustments of the use of thresholds for control of powdery mildew (Blumeria graminis; Jørgensen and Pinnschmidt 2004) and adjustments of recommended doses and timing for the control of septoria leaf blotch (Septoria tritici; Henriksen et al. 2000). In relation to future climate changes, the programme will probably need further adjustments if, for instance, brown rust (Puccinia triticina) becomes more common as an early epidemic disease.

Specifically, the lists of cultivars are updated every year including the latest ranking of the cultivars' susceptibility to different diseases. Growing cultivars with good disease resistance is the most important tool for trying to reduce the potential loss from disease in an integrated control strategy (Jørgensen et al. 2003a). Major differences in resistance and response to fungicide application can be found between cultivars and therefore cultivar resistance is taken into consideration when the disease models in $\mathrm{CPO}$ are used. For each disease in wheat, all cultivars are divided into three groups according to their resistance level. This grouping influences the threshold and the doses recommended. The most commonly grown winter wheat cultivars in Denmark vary significantly in their resistance ranking for leaf diseases (Table 2). The disease ranking for septoria leaf blotch, powdery mildew, yellow rust (Puccinia striiformis) and brown rust is based on national cultivar trials carried out at approximately 15 locations annually or specific small plot trials using artificial inoculation, as it is the case for yellow rust, 
Table 2 Commonly grown cultivars in Denmark 2007 and their disease resistance ranking to the most important diseases

\begin{tabular}{|c|c|c|c|c|c|c|c|c|}
\hline \multirow[t]{2}{*}{ Cultivar } & \multirow{2}{*}{$\begin{array}{l}\text { Yield level } \\
\text { dt ha }{ }^{-1}\end{array}$} & \multirow{2}{*}{$\begin{array}{l}\text { Percent area } \\
\text { grown } 2007\end{array}$} & \multicolumn{6}{|c|}{ Ranking of cultivars to disease resistance $(1-3) 1=$ high resistance } \\
\hline & & & $\begin{array}{l}\text { Septoria leaf } \\
\text { blotch }\end{array}$ & $\begin{array}{l}\text { Powdery } \\
\text { mildew }\end{array}$ & $\begin{array}{l}\text { Yellow } \\
\text { rust }\end{array}$ & $\begin{array}{l}\text { Brown } \\
\text { rust }\end{array}$ & Tanspot & $\begin{array}{l}\text { Fusarium head } \\
\text { blight }\end{array}$ \\
\hline Smuggler & $89.8(101)^{\mathrm{b}}$ & 34 & 2 & 1 & 1 & 1 & 2 & 2 \\
\hline Skalmeje & $88.3(99)$ & 11 & 2 & 1 & 1 & 2 & 2 & 1 \\
\hline Cultivar mixture ${ }^{\mathrm{a}}$ & $89.1(100)$ & 11 & - & - & - & - & - & - \\
\hline Samyl & $88.2(99)$ & 7 & 3 & 3 & 1 & 2 & 2 & 2 \\
\hline Opus & $87.3(98)$ & 7 & 2 & 2 & 1 & 1 & 2 & 2 \\
\hline Robigus & $85.4(96)$ & 7 & 2 & 0 & 1 & 1 & 2 & 2 \\
\hline Abika & 88.4 (99) & 3 & 2 & 0 & 1 & 1 & 2 & 2 \\
\hline Ambition & $94.2(106)$ & 2 & 1 & 0 & 0 & 2 & 2 & 2 \\
\hline
\end{tabular}

${ }^{a}$ The mixture contained Ambition, Smuggler and Skalmeje or Ambition, Abika and Robigus

${ }^{\mathrm{b}}$ Yield relative to the cultivar mixture

tan spot and fusarium head blight (Fusarium spp.). The ranking of cultivars is updated annually by a standing committee to ensure that any changes in susceptibility are included in the database for cultivars as well as in CPO. The cultivar database (www. sortinfo.dk) is widely used by advisors and farmers as the system combines all relevant information on current and prospective cultivars including ranking for disease resistance and estimating the likely cost for fungicide treatments in an average year and cropping situation (Detlefsen and Jensen 2001).

Agronomic evaluation of the system

Results from 38 spring barley trials and 45 winter wheat validation trials carried out in Denmark between 1998 and 2003 are summarised in Table 3.
CPO was validated and compared to various standard treatments, which represent common practices using appropriate doses. In most cases, the standard treatments in wheat cover two to three treatments with a dose ranging from $25-50 \%$ of normal field rate per treatment. Half of the trials were carried out using $2 \times$ $33 \%$ of the standard label rate. In spring barley, a single or split treatment with effective fungicides was used for comparison. In split treatments, $2 \times 25 \%$ of the normal label rate was used, and, when comparing with a single treatment $25-50 \%$ of the normal field rate was used. In both wheat and barley, strobilurins and triazoles were used alone or in mixtures. This was the case for both standard treatments and the treatments recommended by CPO. The results showed that the system gave similar or slightly better disease control and yield responses compared to standard

Table 3 Results on disease control, yields, cost of control and Treatment Frequency Index (TFI) from validation of Crop Protection Online (CPO) in field trials in spring barley and winter wheat

\begin{tabular}{|c|c|c|c|c|c|c|c|c|c|c|}
\hline Crop & Treatment & $\begin{array}{l}\text { No. of } \\
\text { trials }\end{array}$ & $\begin{array}{l}\text { Percent } \\
\text { brown } \\
\text { rust }\end{array}$ & $\begin{array}{l}\text { Percent } \\
\text { septoria } \\
\text { leaf blotch }\end{array}$ & $\begin{array}{l}\text { Percent net } \\
\text { blotch }\end{array}$ & $\begin{array}{l}\text { Percent } \\
\text { powdery } \\
\text { mildew }\end{array}$ & $\begin{array}{l}\text { Yield } \\
\text { increase } \\
\left(\mathrm{dt} \mathrm{ha}{ }^{-1}\right)\end{array}$ & $\begin{array}{l}\text { Net yield } \\
\left(\mathrm{dt} \mathrm{ha}^{-1}\right)\end{array}$ & $\begin{array}{l}\text { Costs of } \\
\text { fungicide }+ \\
\text { application } \\
\left(\mathrm{DKK} \mathrm{ha}{ }^{-1}\right)\end{array}$ & TFI \\
\hline Spring barley & Reference $^{a}$ & 38 & 0.1 & & 2 & & 4.3 & 1.0 & 180 & 0.5 \\
\hline 38 trials & $\mathrm{CPO}$ & 38 & 0.1 & & 2 & & 5.4 & 1.9 & 200 & 0.41 \\
\hline $\operatorname{LSD}_{95}{ }^{\mathrm{c}}$ & & & & & & & ns & & & \\
\hline Winter wheat & Reference $^{a}$ & 45 & & 12 & & 2 & 12.3 & 6.6 & 362 & 0.79 \\
\hline $\begin{array}{l}45 \text { trials } \\
\mathrm{LSD}_{95}{ }^{\mathrm{b}}\end{array}$ & $\mathrm{CPO}$ & 45 & & 10 & & 1 & $\begin{array}{l}13.4 \\
\text { NS }\end{array}$ & 7.7 & 360 & 0.70 \\
\hline
\end{tabular}

\footnotetext{
${ }^{\text {a }}$ Reference treatments have been chosen based on present standards and varies across the trials

${ }^{\mathrm{b}} \mathrm{LSD}_{95}$ values refer to comparison between actual version of $\mathrm{CPO}$ and actual reference treatments
} 
Table 4 Reduction potential in Treatment Frequency Index (TFI) from using Crop Protection Online (CPO) in winter wheat and spring barley assessed in relation to official pesticide statistics for fungicides and the target figures from the pesticide action plan 2004-2009

\begin{tabular}{lll}
\hline & \multicolumn{2}{l}{ TFI fungicides } \\
\cline { 2 - 3 } & Winter wheat & Spring barley \\
\hline Official statistics $^{\mathrm{a}}$ & 0.74 & 0.34 \\
Target for 2009 $_{\text {CPO testing }}^{\mathrm{b}}$ & 0.65 & 0.35 \\
No. of trials & 0.70 & 0.41 \\
\hline
\end{tabular}

${ }^{a}$ Average of 3 years of statistics (2003-2005 sales figures)

b Average TFI fungicide input from 8 years' trial testing of CPO in field trials

treatments although differences were not statistically significant. Overall, the fungicide input was slightly lower compared with the standard treatments.

The optimal input with fungicides depends on the disease pressure and the climate in the individual season, but the susceptibility of the cultivar in particular plays a major role for the optimal input. The differences in margin between resistant and susceptible cultivars are largest in seasons with severe attacks of septoria leaf blotch and yellow rust (Jørgensen et al. 2003a). The dose-response curves for ear treatments targeting control of septoria leaf blotch and yield responses have generally been very flat. The economic optimum in resistant cultivars was a TFI (treatment frequency index $=$ number of standard dosages used) between 0.25 and 0.5 . Most typically, only one ear application was profitable. On more susceptible cultivars, the optimum TFI was $0.5-$ 0.9 , and a two-spray programme gave more flexibility with regard to the dose needed at the second application (Jørgensen and Nielsen 2003b).

Validation trials from the past eight years with fungicides in cereals indicated only a very limited and uncertain reduction potential in fungicide usage (Table 4). The system offers a good opportunity to control disease only if a need can be identified. In general, the CPO recommendations for fungicide input are in agreement with the target figures envisaged by the pesticide action plan 2004-2009. During the past 20 years, a widespread use of reduced doses has led to a significant reduction in fungicide input in winter wheat (Fig. 1). On average, the number of fungicide treatments per season in wheat is approximately two, and the average TFI of fungicides is 0.35 per treatment (Kleffmann-Farmstat 2005; Anon. 2006b).

\section{Investigation of new introductions to $\mathrm{CPO}$}

The results from the ten trials showed quite similar results from using either recommendations from the present version of $\mathrm{CPO}$ or the prototype using regional disease data rather than individual field data (Table 5). In one case, the level of powdery mildew was much higher in the monitoring system compared to the level in the actual field where the trial was carried out. This led to an unnecessarily high input at that site. In the other nine trial sites, the input from the two models was very similar. Generally, the risk of not achieving the best result increases if individual
Fig. 1 Changes in Treatment Frequency Index (TFI) and dose used per application in wheat from 1985 to 2004. (Source: Kleffmann-Farmstat (2005) and pesticide statistics)

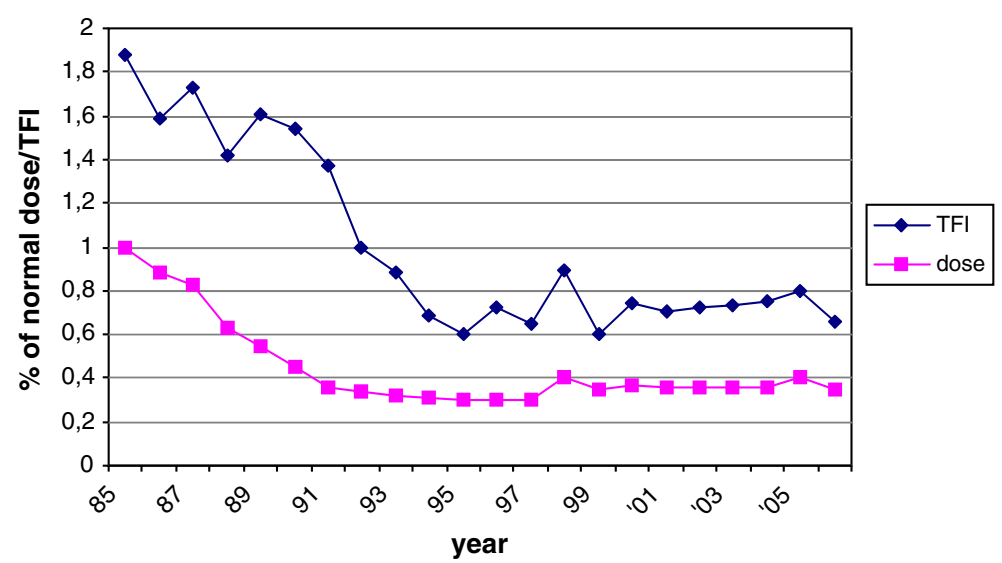


Table 5 Results from 2 years' trials comparing the present version of Crop Protection Online (CPO) with a prototype that does not require specific field assessments

\begin{tabular}{|c|c|c|c|c|c|}
\hline Treatment & $\begin{array}{l}\text { Fungicide input, } \\
\mathrm{TFI}^{\mathrm{a}}\end{array}$ & $\begin{array}{l}\text { Percent powdery } \\
\text { mildew }\end{array}$ & $\begin{array}{l}\text { Percent septoria } \\
\text { leaf blotch }\end{array}$ & $\begin{array}{l}\text { Yield and yield } \\
\text { increase }\left(\mathrm{dt} \mathrm{ha}{ }^{-1}\right)\end{array}$ & $\begin{array}{l}\text { Net yield increase } \\
\left(\mathrm{dt} \mathrm{ha}{ }^{-1}\right)\end{array}$ \\
\hline Untreated & & 1.3 & 20.2 & 74.9 & \\
\hline $\mathrm{CPO}$ & 0.58 & 0.5 & 9.2 & 8.6 & 3.8 \\
\hline CPO prototype & 0.68 & 0.5 & 8.3 & 8.3 & 2.9 \\
\hline $\mathrm{LSD}_{95}$ (ex. untr.) & NS & NS & NS & & NS \\
\hline
\end{tabular}

Average of 10 trials. Net yield has been calculated after costs of fungicides and application have been deducted

a Treatment Frequency Index

field registrations are not carried out. However, the risk seems to be relatively small based on the ten trials carried out during two seasons compared with spraying routinely.

Based on the experiences from these trials and a wish to increase the farmers' direct use of the CPO, the plan is to develop the system in a way that integrates information from the national field database run by the advisory service with regional monitoring data and climatic information. The development of this system occurs initially in a closed group with advisors and farmers in order to investigate if the farmers will find it useful when making decisions on disease control. Further testing of the prototype should preferably be carried out over more seasons and under more variable disease pressure in order to verify the consistency of the system when direct field assessments are not made.

The sociological investigation

The sociological investigation of the farmers' way of making decisions in the area of crop protection identified three types of farmers: (a) system-orientated farmers, (b) experienced-based farmers and (c) advisory-orientated farmers. Several factors were found to illustrate some of the characteristics of the three types (Table 6). None of the three groups of farmers were prepared to carry out very detailed field investigations in order to adjust the input according to need in specific fields (Langvad and Noe 2006; Jørgensen et al. 2007b).

System-orientated strategists generally do not rely on exact field assessments. They tend to manage bigger farms with specialised arable production and demand high levels of disease control. They often carry out treatments following a partially fixed strategic plan, which they have prepared in the winter. This plan is also used as a list for planning purchases of chemicals. Experienced-based strategists base their production on a close, personal knowledge of each individual field, substituting detailed disease assessments with continual more general observations of the fields. The farm size for this group is medium to low. Strategists, who contract their decision-making out to an advisor, i.e. the advisory-contracting decision makers, give higher priority to operations other than growing crops; often they have animal production as their major activity. Typically, they evaluate disease levels in study groups or together with the advisor, but they are not likely to operate a system like CPO alone.

Table 6 Main characteristics of three farmer types - based on their way of making decisions in relation to crop protection

\begin{tabular}{lll}
\hline System-orientated farmers & Experienced-based farmers & Advisory-based farmers \\
\hline $\begin{array}{l}\text { Bigger farms } \\
\text { Systematic approach to planning }\end{array}$ & $\begin{array}{l}\text { Medium-sized farms } \\
\text { Very aware of problems in specific fields }\end{array}$ & $\begin{array}{l}\text { No specific farm size } \\
\text { Often main income from animal } \\
\text { production or other special } \\
\text { production }\end{array}$ \\
$\begin{array}{l}\text { Specialised arable farmers prepare a spraying } \\
\text { plan in winter, which will mostly be followed } \\
\begin{array}{c}\text { during the season } \\
\text { Relative high pesticide input }\end{array}\end{array}$ & $\begin{array}{c}\text { Have no specific spray plan prepared } \\
\text { before the season. Has a 'Learning by } \\
\text { doing' approach } \\
\text { Normal to slightly high pesticide input }\end{array}$ & $\begin{array}{c}\text { Less specific interest in arable } \\
\text { farming. Rely on recommendations } \\
\text { from advisors }\end{array}$ \\
\hline
\end{tabular}


The present CPO prioritises a specific economic value rationale of cost savings by reducing input of pesticides. This strategy and value rationale is different from that of all the three identified groups of farmers. CPO has to be viewed to a greater extent from the end-user's perspective rather than from the perspective of the scientist who developed the systems. An interesting phenomenon was found in the way most farmers view the risks of disease. In practice, this proved to be more closely linked with the risk of possible disruption of their management system, whether in the form of extra work, aesthetically negative consequences (e.g. from lodging or early senescence) or incidents of unacceptably low yields.

Although there is much confidence in the technical content of CPO, the sociological study showed that CPO does not fit in with many farmers' decision strategies. For most farms, crop protection is only a small part of the continuous flow of operations and decision-making made on farms. Decisions on crop protection are not based on isolated economic considerations, but are coupled with a number of other considerations and circumstances including the farm: machinery, manpower, task planning, etc.

The farmer study also provided specific suggestions for improving the system, for example connecting CPO to other computer systems used by the farmers, using CPO to a larger extent in the planning phase and independently of the time of season and giving a larger degree of varied answers that among other things include crop rotations.

Potential use

An increased distribution of CPO depends on the user interface and on the functionality of CPO being targeted to a larger extent at the individual decision strategies. The investigation suggests that DSS have a potential use by approximately $30 \%$ of target users for this kind of tool. This would, however, require that the end-users should be very actively involved in future development processes. The main obstacle to more frequent use is the time-consuming field registrations, which are necessary for the models to calculate field-specific recommendations.

CPO is used among wholesalers and distributors to a limited extent. This group has, however, generally a relatively low impact on the recommendations used by the farmers. Farmers have a long tradition for using information and recommendations given by their own independent DAAS. CPO including both the weed and disease system is broadly supported by the chemical industry. The industry partly supports the research behind the system and typically sees the system as a means of applying and supporting IPM strategies.

The models in CPO have been tested, adjusted and exported to other countries (e.g. Latvia, Lithuania and Poland). This work has underlined the importance of good cooperation between researchers and local advisory services, and the importance of models that are well documented and not too complex. The work has also illustrated that models cannot be transferred directly to new agro-ecological regions but need to be tested and adapted to local regional cropping situations (Bankina and Priekule 2003; Czembor et al. 2003; Semaskiene et al. 2003).

\section{Conclusion}

Scientists generate highly complex knowledge as a basis for developing models in the area of crop protection and pesticide use. However, the information does not always reach farmers as it is presented in a way that does not correspond with the way things are done in practice. Economic analysis of historical trial data shows that CPO models give acceptable recommendations. DSS have proven to be useful tools when pesticide use has to be optimised. This includes spraying only when economic thresholds have been exceeded. Generally, the DSS CPO is valued and trusted for its information, and is widely used by advisors and as a learning tool for students. Often, information given in newsletters to farmers is based on output from the system and as such the indirect use of the system is high. Direct use of DSS by farmers is, however, so far relatively low because the system is not in line with the way most farmers manage their crop protection.

The potential for further reductions in fungicide use in cereals is relatively small in Denmark as a major reduction took place in the 1990s. A major barrier is therefore the lack of economic incentives to change from today's standard treatments. Another major obstacle is the requirement to carry out field registration as part of using the system. Many farmers 
do not find this practicable. This is at least in part linked to the fact that farm sizes are getting larger, leaving less time for decision making at the individual field level. Despite the relatively low use of fungicides in cereals in Denmark, there is still a tendency for farmers to overestimate the risk of disease and therefore to use a dose that is too high or to apply an extra spray. Farmers are generally risk-adverse and concerned about unintended disruption of their management system. They tend to partly overreact, as they are not prepared to risk crop failure or large economic loss due to diseases.

In future developments of $\mathrm{CPO}$, it is recommended that farmers' decision-making practice and their reasoning logic should be addressed. Farmers cannot be considered to be a homogenous group and therefore it is naive to believe that one system will fit all farmers. It is therefore important to acknowledge the major differences and develop different approaches for supporting farmers' crop protection activities. On the basis of our studies it has become evident that a large proportion of arable farmers cannot be reached via CPO directly. To target these other groups, appropriate recommendations based on seasonal variation in disease pressure have proven to be reliable with respect to both disease control and yield. These recommendations are typically given through the DAAS.

\section{References}

Anonymous (2006a). Bekompelsesmiddelstatistikken. Denmark: Miljøstyrelsen.

Anonymous. (2006b). A thematical strategy on the sustainable use of pesticides [(COM 2006 372].

Bankina, B., \& Priekule, I. (2003). Experience of using reduced dosages of fungicides for cereal disease control in Latvia. DIAS report no. 96. Proceedings of the Crop Protection Conference for the Baltic Sea Region, April 2003, Poznan, Poland, pp. 130-140.

Brooks, D. H. (1998). Decision Support System for Arable Crops (DESSAC): An integrated approach to decision support. The 1998 Brighton Conference, Pest \& Diseases. British Crop Protection Council, pp. 239-246.

Czembor, J. H., Horsozkiewicz-Janka, J., \& Nierobca, A. (2003). Testing of Danish decision support system in protection of winter wheat in Poland during 2001-2003. DIAS report no. 96. Proceedings of the Crop Protection Conference for the Baltic Sea Region, April 2003, Poznan, Poland, 165.

Detlefsen, N., \& Jensen, A. L. (2001). Variety selection for winter wheat, sortsvalg. In J. Steffe (Ed.), Proceedings from the third European conference of the European federation for information technology in agriculture, food and the environment, June 18-20, Montpellier, France. Vol. 1, 1-5.

Hagelskjær, L., \& Jørgensen, L. N. (2003). A web-based decision support system for integrated management of diseases and pest in cereals. EPPO Bulletin, 33, 467-471.

Hansen, J. G. H., Secher, B. J. M., Jørgensen, L. N., \& Welling, B. (1994). Thresholds for control of Septoria spp. in winter wheat. Plant Pathology, 43, 183-189.

Henriksen, K. E., Jørgensen, L. N., \& Nielsen, G. C. (2000). PCplant protection - a tool to reduce fungicide input in winter wheat, winter barley and spring barley in Denmark. Brighton Crop Protection Conference. Pest and Diseases, 835-840.

Jørgensen, L. N., Hagelskjær, L., \& Nielsen, G. C. (2003a). Adjusting the fungicide input in winter wheat depending on variety resistance. BCPC conference on Crop Science and Technology, Glasgow, 1115-1120.

Jørgensen, L. N., \& Kudsk, P. (2006). Twenty years' experience with reduced agrochemical inputs. HGCA R\&D conference, Lincolnshire, UK. Arable crop protection in the balance profit and the environment, 25-26 Jan. 2006, 16.1-16.10.

Jørgensen, L. N., \& Nielsen, G. C. (2003b). Septoria control using threshold-based systems and fungicides. Global insights into the Septoria and Stagonospora diseases in cereals. In G. H. J. Kema, M. van Ginkel, \& M. Harrabi (Eds.), Proceedings of the 6th international symposium on septoria and stagonospora diseases of cereals (pp. 4961), 8-12 Dec. 2003, Tunis.

Jørgensen, L. N., Nielsen, G. C., \& Henriksen, K. E. (2000). Margin over cost in disease management in winter wheat and spring barley in Denmark. Proceedings of the Brighton Crop Protection Conference. Pest and Diseases, 655-662.

Jørgensen, L. N., Noe, E., Langvad, A. M., Jensen, J. E., Ørum, J. E., \& Rydahl, P. (2007b). Decision support systems: barriers and farmers need of support. EPPO Bulletin, 37, 374-377.

Jørgensen, L. N, Noe, E., Langvad, A. M., Rydahl, P., Jensen, J. E., Ørum, J. E., et al. (2007a). Vurdering af Plantevarn Onlines økonomiske og miljømossige effekt. Bekæmpelsesmiddelforskning fra Miljøstyrelsen nr. 115 (English summary). http://www2.mst.dk/common/Udgivramme/ Frame.asp?pg=http://www2.mst.dk/Udgiv/publikationer/ 2007/978-87-7052-590-9/html/default.htm.

Jørgensen, L. N., \& Olsen, L. V. (2007). Control of tan spot (Drechslera tritici-repentis) using host resistance. Tillage methods and fungicides. Crop Protection, 26, 1606-1616.

Jørgensen, L. N., \& Pinnschmidt, H. (2004). Yield effects and control of powdery mildew in winter wheat in the presence of septoria. Proceedings of the 11th International Cereal Rusts and Powdery Mildews Conference, Norwich, England.

Jørgensen, L. N., Secher, B. J., \& Nielsen, G. C. (1996). Monitoring diseases of winter wheat on both a field and a national level. Crop Protection, 13, 383-390.

Kleffmann-Farmstat (2005). Statistical data on pesticide use in DK (Company data).

Langvad, A. M., \& Noe, E. (2006). (Re-)innovating tools for decision-support in the light of farmers' various strategies. In H. Langeveld \& N. Röling (Eds.), Changing European 
farming systems for a better future - new visions for rural areas (pp. 335-339). The Netherlands: Wageningen.

McCown, R. L. (2002). Probing the enigma of the decision support system for farmers: Learning from experience and from theory. Agricultural Systems, 74, 1-10.

Noe, E., \& Halberg, N. (2002). Research experience with tools to involve farmers and local institutions in developing more environmentally friendly practices. In K. Hagedorn (Ed.), Environmental co-operation and institutional change. Cheltenham, England: Edward Elgar.

Röhrig, M. (2006). http://www.isip.de online plant protection information in Germany. Abstract from EPPO conference on computer aids for plant protection. Wageningen, 17-19 Oct. 2006.

Rydahl, P. (2003). A web-based decision support system for integrated management of weeds in cereals and sugarbeet. EPPO Bulletin, 33, 455-460.

Rydahl, P., Hagelskjær, L., Pedersen, L., \& Bøjer, O. Q. (2003). User interfaces and system architecture of a web-based decision support system for integrated pest management. EPPO Bulletin, 33, 473-482.

Secher, B. J. M., Jørgensen, L. N., Murali, N. S., \& Boll, P. S. (1995). Field validation of a decision support system for the control of pests and diseases in cereals in Denmark. Pesticide Science, 45, 195-199.

Semaskiene, R., Tamosiunas, K., \& Dabkevicius, Z. (2003). Experience of using reduced dosages of fungicide for winter wheat in Lithuania. DIAS report no. 96. Proceedings of the Crop Protection Conference for the Baltic Sea Region, April 2003, Poznan, Poland. 123-129.

Verret, J. A., Klink, H., \& Hoffmann, G. M. (2000). Regional monitoring for disease prediction and optimisation of plant protection measures: The IPM Wheat Model. Plant Disease, 84, 816-826.

Volk, T., Johnen, A., Newe, M., \& Meier, H. (2003). ProPlant expert.com - The online consultation system on crop protection in cereals, rapeseed, potatoes and sugar beet: Experiences with cereal disease control in the region and possibilities for regional adaptations. Crop Protection Conference for the Baltic Sea Region, April 2003, Poznan, Poland, pp. 103-113.

Weber, M. (1922). The Protestant ethic and the spirit of capitalism. Los Angeles: Roxbury (US), 1998.

Zadoks, J. C. (1983). An integrated disease and pest-management scheme, EPIPRE, for wheat. Ciba Foundation Symposia, 97, 116-129. 